\title{
Co-Transplantation of Mesenchymal Stem Cells and Hematopoietic Stem Cells for Prevention of Graft-versus-Host Disease
}

\author{
Fatme El khansa ${ }^{1}$, Saeid Kaviani ${ }^{1}$, Abbas Hajifathali ${ }^{2}$, and Masoud Soleimani ${ }^{1}$ \\ ${ }^{1}$ Tarbiat Modares University \\ ${ }^{2}$ Shahid Beheshti University of Medical Sciences
}

May 4, 2020

\begin{abstract}
Co-transplantation of MSCs and HSCs has showed controversial results for treatment of GvHD. In this study, the level of predictor factors and GvHD biomarkers have been checked. The co-transplantation of HSCs and MSCs did not show a significant difference compared to the group received MSCs alone.
\end{abstract}

Co-Transplantation of Mesenchymal Stem Cells and Hematopoietic Stem Cells for Prevention of Graft-versus-Host Disease

Running Heads: HSCT with MSCs and GVHD

Abstract:Co-transplantation of MSCs and HSCs has showed controversial results for treatment of GvHD. In this study, the level of predictor factors and GvHD biomarkers have been checked. The co-transplantation of HSCs and MSCs did not show a significant difference compared to the group received MSCs alone.

Key words: HSCT, GVHD, MSCs

\section{Key Clinical Message}

Despite different clinical trials showing controversial results for co-transplantation of MSCs and HSCs for treatment of GVHD, this study found no difference between groups received MCS and HSC and group received MSC alone

\section{Introduction:}

Hematopoietic stem cell transplantation (HSCT) is the last therapeutic approach among the various medical treatments that can cure complicated hematological malignancies, improve dysfunctional hematopoietic stem cells and induce the tolerance in solid organ transplantation. Over past 4 decades, more than one million patients have been treated with HSCT and have benefited from a return to a healthy and effective life. Every day new solutions are applied to the use of HSCT until basic science concepts are fully visualized in the clinic. Despite these successes, many challenges remain, such as understanding the biology of immune cells and their ability to detect malignancies. The valuable findings in this area have led to advances in the use of acquired immune cells such as natural killer cells, $\mathrm{T}$ cells, regulatory cells and the application of new therapeutic approaches for serious hematological malignancies and other disorders(1). GvHD is the main cause of allogeneic stem cell transplant related mortality and occurs when donor's $\mathrm{T}$ cells do not show tolerance against specific proteins on host cells(2). There are two kinds of GvHD. Acute form (aGvHD) that usually occurs before 100 days of transplantation. If it occurs 100 days after bone marrow transplantation, it is considered as a chronic $\operatorname{GvHD}(3)$ Of course this classification is not accurate and it is said that it should be confirmed by assessing the biopsy of the affected organ. On the other hand, there are some other disorders 
that occur in the skin, Gastro intestinal tract or liver that are not related to GvHD such as CMV related diarrhea(4). Based on the source of the donor and the similarity of the patient with the donor in terms of HLA, aGvHD occurs in between 30 and $80 \%$ of hosts (5). There are several methods for prevention and control of GVHD, including corticosteroids (especially prednisolone) as the first line therapeutic approach. But drug resistance to immunosuppressive drugs in some patients on one hand, and infection due to overuse of them on the other hand, has failed this treatment in 30-40\% of transplanted patients(6).It is now believed that substituting preventive methods for GVHD rather than treating it is more reliable. Mesenchymal Stem Cell (MSC) Therapy as a new therapeutic approach has been used for reducing the risk of GvHD(7).

Specific features of MSCs such as, low MHCI expression and non-MHCII expression, presence of co-stimulatory molecules CD80, CD86 and CD40 (8, 9), inducing the down regulation of IFN $\gamma$ by Th1 and increasing the secretion of IL12 BY Th17, inducing the secretion of IL4 by Th2, increasing the regulatory T cells, induction of peripheral tolerance and inhibition of proinflammatory immune response(10-12) have made these cells as a great candidate for bone marrow transplantation. These cells co-localize with HSCs in normal bone marrow and produce factors that recruit and regulate stem cells(13). It has been shown that co-transplantation of MSCs and HSCT reduce the risk of GvHD and is also effective in the treatment of GvHD. Numerous studies have shown different results and even $100 \%$ efficacy has been reported(14). And also it is reported that in the case of using these cells from day zero (day of HSCT) to $30^{\text {th }}$ day, they can have a role of prophylaxis for GvHD and from day 30 onwards play the role of treatment for graft-versus-host disease(2). In a study, 4 biomarkers 1L2Ra, TNFR1, HGF, and IL8 were identified with increased expression in the serum of patients with $\mathrm{GvHD}(15)$. Another study showed that high concentrations of these cytokine receptors at days 14 and 21 were significantly correlated with the likelihood of $\operatorname{GvHD}(16)$. Soluble IL-2R has also been shown on day 7 be to a predictive factor for $\operatorname{GvHD}(17)$. Approximately $60 \%$ of patients develop acute gastrointestinal GvHD after Alo-HSCT. REG3a (regenerating islet-derived 3-alpha) is a type C lectin secreted from paneth cells and its plasma concentration is associated with disease activity in inflammatory bowel disease, and some studies have suggested that as a biomarker for gastrointestinal GvHD (18, 19).TNF- $\alpha$ (tumor necrosis factor $\alpha$ ) induces GVHD by enhancing the amplification of donor immune responses against host tissues and direct toxicity to target organs. Studies have shown that changes in plasma TNFR1 levels are associated with the severity and incidence of GVHD and survival of patients. It has also been suggested that if the three markers sIL-2R, sCD8 and sTNFR1 be examined simultaneously, it will be possible to detect aGVHD before the appearance of $\operatorname{symptoms}(20,21)$. It is noteworthy that REG3 $\alpha$, which is secreted from paneth cells, has a regulatory effect for Gram-positive gastrointestinal bacteria and can differentiate between GVHD-induced diarrhea from non-GVHD one. REG3 $\alpha$ is one of the most important biomarkers confirmed for aGVHD(22). TNFR1 is a receptor for the inflammatory cytokine TNF $\alpha$ that can change to the soluble form after binding to its ligand. Although this biomarker is not specific for aGVHD, its level is strongly correlated with the severity of GVHD, response to treatment, mortality from any factor except of relapse and patient survival(20). ST2 is a receptor against IL33 and is secreted in response to inflammatory stimuli and induces an inflammatory phenotype in T lymphocytes(23). The sDNAM1 molecule (sCD226) (An activating immunoreceptor) is a member of the super immunoglobulin family that is expressed on the surface of $\mathrm{T}$, NK cells and large number of hematopoietic and non-hematopoietic cells. The soluble form of this molecule is also available in plasma. Recently, sDNAM1 has been implicated in the pathogenesis of aGVHD(24). Since sDNAM1 is a potential biomarker for predicting aGVHD on day 7 (7 days before transplant), we have planned to measure the concentration of that in patients' serum prior to HSCT and afterwards to confirm the effect of co-injection of MSC with HSCT. By examining the panel of TNFR1, REG3 $\alpha$ and ST2, we can assess the risk of GVHD-induced NRM, and by monitoring the serum level of sDNAM1, we can evaluate the probability of aGVHD occurrence and finally evaluate the effect of MSC injection on outcome of transplantation.

Given that co-injection of MSC with HSCT has a significant role in modulating the immune system and may possibly prevent GVHD as the deadliest complication of hematopoietic stem cell transplantation, The aim of this study was to evaluate the effect of simultaneous injection of MSC with HSCT and to monitor its efficacy through serial examination (days $7+,+14+,+21+$ and +28 ) of TNFR1, REG3 $\alpha$, ST2 and 
SDNAM1.

\section{Materials and Methods:}

\section{Sample preparation}

For bone marrow sampling, after obtaining written informed consent from two donors and reviewing histories including history of malignant diseases, autoimmune diseases, hypertension, diabetes and history of drug use, traveling abroad and other important aspects, human Immunidificiency virus 1,2, Hepatitis B virus evaluation, Hepatitis C virus evaluation, diagnostic tests for evaluation of Treponema Pallidum (syphilis), Toxoplasma Gond and Cytomegalovisus were performed for patients. After examining the results of the test and excluding all risk cases, 2 to $5 \mathrm{ml}$ bone marrow aspiration were prepared and were transferred to the laboratory under sterile conditions in a heparin-containing tube.

\section{Isolation of Bone Marrow Mesenchymal Stem Cells:}

Initially, 10-15 $\mathrm{ml}$ of bone marrow samples were prepared. The bone marrow sample was diluted 1: 1 with PBS, then it was slowly poured onto the ficoll, and the cells were centrifuged at room temperature for 20 min at room temperature with minimal acceleration and braking. After re-centrifugation, the mononuclear cells were separated and diluted in PBS (2: 1) and centrifuged again at room temperature at $400 \mathrm{xg}$ for 10 min. The cell pellets were counted and centrifuged again at room temperature for 4 min at $400 \mathrm{xg}$. At this stage, the cell pellets were suspended in DMEM medium containing $10 \%$ FBS at a concentration of $10^{7}$ cells

/ ml. Approximately $30 \mathrm{ml}$ of culture medium containing FBS was added to each sample and cells were cultured at approximately 50,000 cells/cm in T-175 flask ( $1 \mathrm{ml}$ of mononuclear cell suspension to $30 \mathrm{ml}$ of flask culture medium). The cells were slowly mixed in the culture medium and the flasks were transferred to a $37^{\circ} \mathrm{C}$ incubator with $50 \% \mathrm{CO}$. After 4 to 7 days, non-adherent cells were removed by supernatant removal and $30 \mathrm{ml}$ of fresh medium was added to the flask. Culture medium was replaced twice a week. After 5 to 10 days of plating (in some cases more) MSCs cells reaching $80-90 \%$ density, were moved into other flasks.

\section{Cell Passage:}

After 10 to 15 days of culture, the cells were passaged at a density of over 80-90\% (cells could be frozen in each passage). For cell proliferation, cell passage was repeated every $5-7$ days or when cells reached $75-85 \%$ density.

\section{MSC harvest:}

After 4 weeks of culture (approximately 28 days), MSCs were harvested via harvest medium (including $5 \%$ PBS and FBS) and centrifuged (800xg for 15 minutes) and then were suspended in administration buffer (PBS and 2.5\% human albumin). MSCs were then washed and counted and diluted (2x106 cells $/ \mathrm{ml})$ before freezing in administration buffer.

\section{Cell freezing:}

Sterility, mycoplasma and endotoxin tests were performed on the cell supernatant. $1 \mathrm{ml}$ of washing solution (PBS / 5\% FBS) was added to $1 \times 10^{7}$ cells. The cells were then placed on ice for $10 \mathrm{~min}$ and then they were added to the freezing solution (20\% DMSO, 40\% HSA, 40\% PBS) and placed in liquid nitrogen.

\section{Assessing the surface markers by flow cytometery}

Cell specificity was assessed by assessing surface markers using antibodies PE-34CD, FITC-44CD, FITC45CD, FITC-73CD, FITC-90CD, PE-b11CD, PE-29CD and FITC-105CD (PE-1IgG and FITC-). 1IgG was used as an isotype control.

\section{Complementary tests to confirm mesenchymal stem cells}

In order to confirm the cell specificity, differentiation into bone, adipose, and cartilage was done by Alizarin Red, Oil red and Toluidine Blue staining. 


\section{Karyotype of bone marrow-derived mesenchymal stem cells}

When the cell density reached $80 \%$, colcemid was used to stop the cell cycle. Changes in cell morphology were monitored by inverted microscopy. After cell separation with trypsin, centrifugation was performed (400 $\mathrm{g}$ for $10 \mathrm{~min}$ ). $5 \mathrm{ml}$ of $0.075 \mathrm{M} \mathrm{KCL}$ solution with hepes was carefully and slowly added and then incubated in $\mathrm{C} 37^{\circ}$ for $30 \mathrm{~min}$. After centrifugation $(300 \mathrm{~g} \times 5 \mathrm{~min}), 5 \mathrm{ml}$ of fixative solution containing acetic acid and methanol mixture (methanol: acetic acid ) was added to the cell pellet. The centrifugation was performed again with the previous speed and time. The fixative solution was discarded and the samples were washed twice in cold $\left(5^{\circ} \mathrm{C}\right)$ fresh methanol: acetic acid solution (1:2) to improve metaphase quality. The slides were incubated at $60^{\circ} \mathrm{C}$ for at least 16 hours to obtain G-bands. They were then immersed in trypsin solution $(0.002 \mathrm{~g} / \mathrm{ml})$ for 5 seconds and washed in saline solution and finally washed rapidly with distilled water. Staining was performed using Giemsa (6:1) dye (Trypsin and Giemsa) and the bands quality was evaluated.

\section{Determination of TNFR, DNAM- and ST2 levels by ELISA}

First, all reagents and samples reached room temperature before use. TNFR, DNAM-1 and ST2 levels were measured according to the protocols of Quantikin ELISA respectively. From all patients' samples, controls and standards two samples were prepared. Tests were carried out according to the protocol. Based on OD results the mean results was counted. Log/lag curve was used for showing the results.

\section{Data analysis method}

Data were described using tables and charts. The data were analyzed by Kaplan-Meier nonparametric method and life table method. The logarithm test was used to compare survival rates and $\mathrm{p}<0.05$ was considered as the significant level. T-Test and chi-square test were performed for analytical and descriptive analysis using spss22 software, and software was performed for survival time model.

\section{Patients:}

10 patients were considered in this study. Patients included in the study were candidate for allogeneic hematopoietic stem cell transplantation with a donor with DNAM-1 above $8 \mathrm{ng} / \mathrm{ml}$. Five patients were in the MSC pulse HSC injection group and five patients in no MSC group. A total of 5 men and 5 women were enrolled. The mean age of the patients in the MSC recipient group was $27.8+8.49$ and in the non-recipient group was $36+12.76$. The MSC recipient group consisted of 2 males and 3 females and the non-MSC recipient group consisted of 3 males and 2 females. All patients underwent BU/FU Myeloablative chemotherapy regimen including busulfan $0.8 \mathrm{mg} / \mathrm{kg}$ every 6 hours for 4 days and fludarabine $30 \mathrm{mg} / \mathrm{m} 2$ of body surface (IV) for 5 days. Cyclosporine and methotrexate were considered as a prophylaxis regimen for patients with GvHD. CysA was administered to patients at a dose of $3 \mathrm{mg} / \mathrm{kg} /$ day a day before transplantation (day -1). The duration of prophylactic effect of cyclosporine was 6 months and in the absence of symptoms in 3 months, the dose was reduced. The initial dose of MTX was $+10 \mathrm{mg} / \mathrm{m} 2$ on day +1 and then $+6 \mathrm{mg} /$ $\mathrm{m} 2$ on days $+3,+6$ and +11 . Mesenchymal stem cells were injected into the MSC recipient group 1 hour before the injection of hematopoietic stem cell transplantation and $24 \mathrm{~h}$ after transplantation. The dose of BM-MSC for injection was $1-2 \times 10^{6}$ cell $/ \mathrm{kg}$ (Table 1,2 ).

\section{Result:}

Cell morphology was assessed by invert microscopy then the The phenotype of stromal cells isolated from bone marrow was determined using surface marker analysis. Bone marrow-derived MSCs were positive for specific markers CD29, CD44, CD73, CD90 and CD102 and did not express any HSC markers including CD11b, CD34, CD45, and HLA-DR. Differentiation to osteoblasts, adipose and chondrocyte was performed. Figures are not shown here.

\section{Genetic analysis of mesenchymal stem cells extracted from bone marrow}

In order to evaluate the genetic health of mesenchymal cells isolated from bone marrow and no changes in chromosome of these cells, cells cultured in passage 3 were used for karyotyping. The cells had normal chromosomal pattern and no change was observed (figure1). 


\section{Transplantation results in two groups of patients:}

From all patients, Just 5 people faced with GvHD. 2 of them were in the MSC + HSC group and 3 in the control or HSC group alone. The incidence of GVHD in the MCC receiving group was $104.5 \pm 21.90$ days post transplantation and in the control group was $35.66 \pm 10.69$ days.

The mean WBC grafting time in the MSCs + HSCs group was $10.6 \pm 2.70$ days and in the non-recipient roup was $9.4 \pm 0.89$ days ( $\mathrm{p}$-value $=0.39$ ) and No significant difference was observed. And also there was no significant difference in platelet engraftment time between two groups. Platelet engraftment was $12.6 \pm 3.78$ in HSC + MSC group and 11 \pm 2.54 in HSCs group (p-value $=0.45$ ). WBC engraftment was defined as a first day of three consecutive days where the WBC was greater than $1000 \times 10^{3} / \mathrm{L}$ and platelet engraftment was defined as a first day of three consecutive days when platelet counts were obtained without platelet count of $2000 \times 10^{3} / \mathrm{L}$. There was no significant difference in the incidence of GVHD in the two groups of patients $(2$ patients with grade 1 and $4 \mathrm{GvHD}$ in MSC recipient group and 3 patients in control group). However, the duration of transplantation until the onset of GVHD in the MSC + HSC recipient group was longer than that of the HSC recipient group (104.5 \pm 21.90 vs $35.66 \pm 10.69)$.

According to Table 3, the mean age in MSC recipient group was $27.80 \pm 8.49$ and in another one was $36 \pm$ 12.76. The average GVHD initiation time for MSC recipient group was $104.5 \pm 21.90$ and in another group was 35.66 \pm 10.69 . The average time for Plt engraftment in MSC recipient group was $12.6 \pm 3.78$ and in another group was $11 \pm 2.54$. The mean time for WBC engraftment for MSC recipient group was $10.6 \pm 2.70$ and in the control group was $9.4 \pm 0.89$.

According to Table 4, there was a significant difference in the average GVHD initiation time (day) between MSC + HSC group and HSC group alone (P-Value $=0.01)$, on the other hand, the average time of Plt engraftment and WBC engraftment were not significantly different between the two groups according to their p-value of 0.45 and 0.39 , respectively. However, injections of MSCs in patients have been shown to prolong the duration of transplantation day until the occurrence of GvHD and generally decrease the severity of GvHD in these patients, but, the small number of patients in this study did not yield accurate conclusions.

Examining the trends of factors over different days in MSC recipient group:

According to figure 2, the average trend of DNAM factor in MSC recipient group is higher than that of MSC non-recipient group over time, which is much higher in day 7 than in the recipient group.

As its shown in figure 3, the mean trend of TNFR factor in MSC recipient group was higher than that of non-MSC recipient group before day 14, but this trend was reversed from day 14.

Regarding to Figure 4, it was obvious that the mean ST2 factor was increased in both groups but from day 7 this trend was higher in MSC recipient group than in control group.

Evaluation of mean difference of factors per day in two groups of MSC recipient and nonrecipient

\section{TNFR1 factor}

By examining TNFR ratio on days 7, 14, 21 and 28 compared to pre-transplantation, it was observed that this level was enhanced in both MSCs + HSC and HSC groups on day 7 which could be caused by conditioning regimens. Since TNF- $\alpha$ is one of the most important factors of inflammation, following mucosal and subsequent epithelium injury and initiation of inflammatory pathways, the alternative marker of this inflammatory factor also increases in the plasma of transplanted patients. In the mesenchymal stem cell recipient group, this ratio decreased earlier than in the HSCs alone. However, there was no significant difference in the ratio of TNFR1 on different days between two groups (Table.5)

According to Table 6 (considering p value: 0.05) both groups showed there was no significant difference in mean values of TNFR between two groups on different days.

DNAM-1 factor 
Due to the important role of the interaction between DNAM-1 and its ligand in the development of aGvHD, patients with higher DNAM-1 levels are assumed to exhibit higher GvHD. All patients selected for this study had a DNAM-1 level higher than $8 \mathrm{ng} / \mathrm{ml}$ at baseline (above the mean in normal subjects). Based on previous studies and the prognostic role of this marker in the incidence of GvHD, patients with higher level of DNAM-1 were selected for co-transplantation of MSCs and HSCs. According to Table no. 7, comparing the mean DNAM factor for each day in two groups, a significant difference is shown on day 7 with P-VALUE equal to 0.03 and less than 0.05 . But in other days we did not see a significant difference between two groups with P-VALUE higher than 0.05( Figure 5).

\section{ST2 factor}

Studying different levels of ST2 factor in specific days, due to the P VALUE, showed no significant difference on days 0 to 28 in two HSC+MSC and MSC recipient groups (Table 5,8 ).

\section{Association between ST2 level and GvHD risk}

The average level of ST2 for all patients on day 14 was $39.48 \pm 17.78$ and on day 28 was $37 \pm 18.93$. Given the these days ST2 level in patients and also based on previous studies in this area, a ST2 level of $33 \mathrm{ng} / \mathrm{ml}$ was used as the basis for measuring the difference in patients between high ST2 and low ST2 levels. The relationship between ST2 levels on day 14 and day 28 and onset of GvHD in patients was investigated. Of the 10 patients included in the study, 5 had grade II-IV GvHD. According to Table 9, the relation between GvHD and the standard deviation of ST2 in day 14 and 28 was parallel with the GvHD severity (Figure 6).

\section{The association between TNFR ratio and GvHD risk}

To investigate the association between TNFR ratio in the first days after transplantation, which is the most frequent inflammatory phase induced by chemotherapy, according to previous studies [144] the ratio of 2.5 was used as a baseline to differentiate between the patient groups. As a biomarker for predicting GvHD, it was shown that at day 14 after transplantation, patients with a TNFR ratio greater than 2.5 were at a higher risk for GvHD occurrence up to 180 days after transplantation. (P-Value $=0.01$ )(Figure7 and Table.10).

\section{Discussion:}

Allogeneic hematopoietic stem cell transplantation is an effective treatment for patients with hematologic malignancies who have HLA-compatible or incompatible donors(25). Patients are prepared with chemotherapy or radiotherapy and then hematopoietic stem cells are injected intravenously. Shortly after injection, hematopoietic stem cells leave the bloodstream and are replaced in the extravascular space, thereby cells are transplanted into the patient's bone marrow. During a successful transplant, hematopoietic stem cells proliferate and begin hematopoiesis in the patient's bone marrow. Hematopoietic stem cell transplantation depends on several factors, including: the severity of the preparation regimen, the dose of the transplanted stem cells, the degree of incompatibility, the T-cell graft content, and the severity of post-transplant immune suppression $(26,27)$. However, a major problem in HSCT patients is graft-versus-host disease that occurs in both acute and chronic forms and can be the leading cause of death in these patients(28). Grading systems have been developed to determine the severity of GvHD; patients with Grade III and IV aGvHD have been estimated to have a 5 -year survival of $25 \%$ and $5 \%$, respectively, and an increase in cGvHD severity is correlated with increased mortality (1). Other major causes of mortality are relapse (approximately $30 \%$ of deaths) and infection (approximately 10\% of deaths), and most deaths occur within the first two years after transplantation $(28,29)$. Various therapeutic strategies have been discovered to reduce the incidence of GvHD and recurrence, one of them is the use of MSCs as a cell-based approach. Mesenchymal stem cells are multipotent progenitors that can be isolated from various sources such as adult bone marrow, adipose tissue, and various embryonic tissues and have the ability to differentiate into different cell and tissue lineages such as chondrocytes, osteoblasts, and adipocytes. However, cord blood and bone marrow are the most common sources of MSCs for clinical use. MSCs have been shown to release numerous colony-stimulating factors and cytokines, both permanently and after stimulation. These cells are also able to support the prolonged proliferation of initiating culture cells in vitro and to increase the engraftment in preclinical models 
$(30,31)$. In addition, MSCs have been shown to have potent suppressive activity that actually targets all types of blood cells(32-34). Since proliferative MSCs in the culture medium can be injected intravenously without toxicity, these pre-clinical studies have rapidly developed to therapeutic applications that increase HSCT engraftment and reduce the incidence and severity of $\operatorname{GvHD}(35,36)$. In the extracellular environment, MSCs enhance hematopoiesis and inhibit Tcell proliferation, NK cell cytotoxicity, and dendritic cell differentiation(25).Previous studies have shown that co-injection of MSCs with HSCs can support and improve transplantation outcomes and prevent severe acute GVHD. Pre-clinical studies have shown improved engraftment of HSCs and reduced risk of GvHD after simultaneous injection of proliferated MSCs and $\mathrm{HSCs}(27$, 37-39) and this has led to further clinical studies and investigations based on MSC therapy with the aim of improving the outcome of allogeneic HSCT transplantation in patients with hematologic malignancies. However, although numerous clinical and preclinical studies have been performed with MSCs, the efficacy of MSCs in transplantation conditions is still unclear. The aim of this study was to evaluate the effect of co-injection of MSCs with HSCs in allogeneic transplantation of patients with hematologic malignancies for further analysis of GvHD and engraftment. The results of this study showed that there was no significant difference in WBC and platelet engraftment between two groups of study, however, faster engraftment was seen in group of MSC+HSC transplantation. MSCs produce cytokines that support hematopoiesis and thus can potentially enhance bone marrow recovery such as G-CSF that can reduce the effects of MSC injection on transplantation(26). In a meta-analysis study conducted by Merete Kallekleiv et al. In 2016, the findings of several clinical trials were evaluated and summarized to assess the effect of co-injection of MSC and HSCs on transplant outcomes such as engraftment, GVHD, relapse. And the results showed that when MSC was injected within 24 post-HSCT, it did not improve neutrophil engraftment time and no significant statistics was observed (26). Kaiyan Liu and colleagues showed in a study that co-injection of MSCs and HSCs resulted in a faster increase in platelet concentration $\left(500 \times 10^{9}\right.$ cells / L) (29). In this study, as in the present study, there was no significant difference between platelet engraftment in the treatment and control groups. However, over a period of 100 days, the time to reach platelet count to $50 \times 10^{9}$ cells / L in the treatment group was significantly shorter than the control group. In a study by Ball et al. (2008), recovery of lymphocytes, especially NK cells, was faster in patients receiving MSCs than in control patients(35). In the present study, there was no significant difference in WBC engraftment between two groups. In this study, it was hypothesized that maybe the accelerated WBC engraftment time be dwindled by administration of G-CSF in the early posttransplant phase. As Ringden et al.(40) have observed, treatment with G-CSF accelerates neutrophil but not platelet engraftment. In another study conducted by Wu et al. (2013), cord blood derived MSCs were shown to accelerate neutrophil and platelet engraftment in recipient of HSCs with the same source. This study has shown that patients receiving UCMSCs not only have faster engraftment compared to cord blood HSC alone, but also the clinical application of third donor proliferated UCMSCs is safe and feasible. This study suggests that MSCs play an important role in stabilizing specific bone marrow-specific microenvironment for hematopoiesis by providing appropriate scaffolding and secretion of different cytokines, adhesion molecules, and extracellular matrix proteins and it be mentioned that chemotherapy and radiotherapy pre-transplantation can damage bone marrow stroma(34,41). Simultaneous injection of MSC and HSC can have a major impact on bone marrow regeneration, especially when the number of available HSCs is limited like cord blood HSC transplantation. As Macmillan reported in a 2009, transplantation of proliferated BM-MSCs originated from haploidentical parents lead to better engraftment in pediatric transplantation with cord blood HSCs(42). In a study by Frassoni et al and colleagues, they simultaneously injected mesenchymal stem cells derived from patients (identical donors for HLA) and hematopoietic stem cells to enhance HSC engraftment. Their results showed a higher platelet count at day 50 after transplantation in the treated group with MSC and HSCs(43). These results may be due to MSCs' support for hematopoietic microenvironment and/or release of soluble factors to enhance HSC engraftment. MSCs have been shown to be able to regenerate bone marrow after direct injection into the BM $(43,44)$. In addition, after systemic injection of MSCs in animal models, they have been identified BM and can enhance the engraftment of HSCs (45-47). These results suggest that MSCs are able to migrate to bone marrow and support hematopoiesis. However, other recent studies have suggested that based on the observations of transient and weak MSCs engraftment after systemic injection, soluble factors released by MSCs may also play a role in HSCs engraftment. MSCs have been shown to 
produce several growth factors that improve HSC growth and differentiation, as well as the chemokines and chemokine ligands that are important in migration of HSCs into bone marrow (48-51). In another study, K Le Blanc and colleagues treated 7 patients with MSCs with allogeneic HSCT. And reported that co-infusion of MSCs and HSCs results in rapid neutrophil and platelet engraftment and 100\% chimerism, and subsequently reduces the likelihood of severe acute GVHD and infections(7). In one study, Le Blanc used co-injections of MSCs and HSCs for 3 patients with previous failure in transplantation and 4 patients with SAA in order to increase the engraftment, but the engraftment was not compared with any control group(42). The results of a study by Lynne M. Ball et al. (2007) showed that simultaneous injection of MSCs and HSCs could regulate alloreactivity in donor and enhance the engraftment of HSCs to the BM of recipient and thereby reduce the risk of graft failure(52). The results of these two studies were different from those of the present study, which may be due to the low number of patients in our study and further studies are needed to determine the precise impact of MSC on engraftment. Although there are still differing views on the effects of MSCs on HSC engraftment, most published data have shown that simultaneous injection of MSCs and HSCs is feasible and safe (53). As stated previously, in in vitro condition, MSCs support hematopoiesis and on the other hand, inhibit T cell proliferation, NK cell cytotoxicity, and dendritic cell differentiation(27). In animal models, co-injection of MSCs and HSCs has been shown to induce long-term post-allograft survival in baboons and also to prevent GvHD in some mouse models as well as in aGvHD xenograft models (human to NOD / SCID mice) by increasing the production of regulatory T cells $(28,29$, 43). Past studies have shown that co-administration of stromal cells may support hematopoietic / lymphopoietic donor transplantation and prevent severe aGvHD(54). Some studies have shown that injections of MSCs can treat severe GVHD. Immune system-mediated inhibition of mesenchymal stem cells is a complex mechanism involving changes in the maturation of antigen-presenting cells and in the system of cytokine secretion and inhibition of monocyte differentiation into dendritic cells. These cells induce immunosuppressive regulatory lymphocytes and CD8 apoptosis and thus inhibit the immune system(38). In the present study, the symptoms and grade of GVHD were more severe in the control group than in the mesenchymal stem cells treated group. But there was no statistically significant difference in the incidence of GVHD between the two groups. The reason for the lack of significant difference can be due to the low sample size. However, the incidence of aGvHD in MSC contained group was shorter in 5 treated patients compared to the control group. The results of this study are comparable with previous reports in patients undergoing allogeneic transplantation of HLA-compatible siblings $(46-49,55)$.

In a meta-analysis study performed by Hillard M. Lazarus et al. "Evaluating the overall incidence of acute and chronic GVHD", acute GVHD (grade 1-2 or grade 3-4), and chronic GVHD (classified into two limited and widespread groups), no significan no statistically significant difference between the two groups in the treated and treated mesenchymal stem cells. In this study, they believe that co-injection of cultured MSCs with HSCs is safe and possible. However, evaluation of the appropriate dose of MSCs and the number of injections to prevent or treat GVHD during allogeneic HSCt in phase 2 clinical trials should be performed(27), and also in a study by Kaiyan Liu and colleagues its suggested that MSCs injection was not effective in preventing GVHD. They stated several reasons for this finding. As shown in previous studies, the main source of patients post-transplant MSCs is from host. So, MSCs can only inhibit the patient's immune system for a specific period after injection. Therefore, it is difficult to see the positive effects of MSCs when the patient's immune system is severely inhibited. The mechanism of immune suppression by mesenchymal cells in the body is also unclear, and further studies are needed to determine the amount of cytokines produced by GVHDassociated mesenchymal stem cells to determine whether injections of mesenchymal cells can effectively prevent the GVHD or not(29). In another study, Y. Tian and his colleagues reported different results. Their results showed that co-injection of MSCs and HSCs into the body could act as an immune suppressor and protect the allogeneic graft receptors against GVHD and prolong their survival time. They said the T cell homeostasis and enhancement of CD4 + CD25 $+\mathrm{T}$ cell proliferation are the main reasons for this result. In another study conducted by F. Baron et al on 20 HLA-incompatible patients, it was shown that injection of MSCs 2 to $0.5 \mathrm{~h}$ before allogeneic transplantation led to a reduction in the incidence of aGvHD grade IV and is comparable to its incidence rate in patients undergoing allogeneic transplantation from HLA-compatible unrelated donors (without MSCs)(27). The results of this study suggest that MSCs can prevent GvHD related 
death in patients receiving PBSCs from HLA-compatible unrelated donors. In another study by Ning et al in 2008, they compared the co-injection of MSCs and HSCs in 10 patients with a 15 controls. It was shown that just one patient in MSC receiving group showed grade II GvHD compared to 8 controls. The overall incidence of aGvHD in MSC receiving group was $44 \%$ and in the control group was $73 \%$. In this study, it was shown that co-injection of MSCs at even lower doses than previously reported $\left(0.3-1.5 \times 10^{6}\right.$ cells $\left./ \mathrm{kg}\right)$ is able to prevent $\operatorname{GvHD}(54)$. These findings indicate that MSCs can have clinical applications for the engineering of transplantation strategies in allogeneic HSCT (39). In a study, K Le Blanc and colleagues treated 7 patients with MSCs and HSCs. None of the patients had GVHD. In this study the reason for the lack of severe GVHD was the effect of MSCs on immune system regulation and donor cell chimerism(54). According to several mouse transplantation studies that have shown the role of MSCs in tumor growth in vivo $(56,57)$, adverse effects of co-injection of MSCs and HSCs with immunosuppression have been investigated in other studies. In fact, MSCs are able to inhibit allogeneic T cell responses and suppress T-cell proliferation by cell-cell interactions and soluble factors (58-61). Suppressed T-cell function is able to attenuate or eliminate graft versus leukemia (GVL) in allograft conditions. There is no evidence showing that MSCs were able to selectively suppress GvHD but did not affect GVL(62).

In melanoma, co-injection of MSCs and allogeneic tumor cells results in faster tumor growth, even when MSCs migrate to distant areas. This suggests that MSCs may suppress systemic immune function(56). Another report showed a mismatch between the in vitro and in vivo behavior of MSCs. MSCs inhibit the proliferation of malignant cells with hematopoietic and non-hematopoietic origin in vitro, by stopping tumor cells in the G1 phase of the cell cycle. However, when tumor cells plus MSCs were injected into NOD / SCID mice, tumor growth was faster than in the group receiving only tumor cells. The authors propose that MSCs may maintain the ability of self-renewal of cancer cells and this is a new mechanism by which the stromal environment can affect the process of malignant disease(63). The results of this study showed no significant difference in recurrence after transplantation. In the MSC recipient group, one patient died of recurrence and one patient died of GvHD, while in the control group consisted of 5 patients, 2 patients died because of GvHD and one patient died because of severe immunosuppression related infection due to immunosuppressive therapy. So the results showed no significant difference between MSC injection and recurrence. In a study by Baron et al with 20 patients, co-injections of MSCs and HSCs did not eliminate the effects of GVT, and a one-year recurrence in the MSC-treated group was reported 30\% and it was similar to the recurrence in the control group(31). There was no significant difference between the two groups in the study by Lee et al(64). The only study that reported a significant difference between the MSC group and the control group was by Ning et al. with 20 patients in 2008(65). The clinical trial reported that patients receiving MSC had a significantly higher rate of relapse (60\% vs $20 \%$ in the control group). In addition, the median time from transplantation to recurrence was shorter in MSC recipient group than in the control group (63 day vs 177 days). In fact, the study by Ning and his colleagues confirmed some of the previous findings that MSC may help tumor growth. Plasma biomarkers are important factors in the diagnosis of acute GVHD after HSCT. Studies have recently been conducted to find and validate the biomarkers associated with GVHD. In this study, the levels of TNFR1, ST2 and DNAM-1 markers were measured on days 7, 14 and 28 post-transplantation for prediction of GVHD. Several biomarkers (or combinations of biomarkers) have been associated with greater chance of GvHD occurrence, clinical improvement of GvHD symptoms, steroid resistance, and overall survival $(56,66,67)$. For this reason, a panel of soluble factors that have previously been reported to be involved in GvHD was evaluated in this study. DNAM-1 is a member of the immunoglobulin family and is expressed permanently in most CD4 + T cells, CD $8+\mathrm{T}$ cells, NK cells, and monocytes $(32,33)$. DNAM-1 ligands are CD155 and CD112 that are expressed on hematopoietic and nonhematopoietic cells including epithelial and endothelial cells(31, 64). Interestingly, the expression of CD155 and CD112 is regulatory increased with DNA damage response pathways in response to chemotherapy(65). Interaction between DNAM-1 and CD8 + T cells and NK cells and its ligand on the surface of target cells increase the cytotoxicity of cells $(32,66)$. In addition, DNAM-1 is involved in a range of $\mathrm{T}$ cell functions. Various studies have shown the critical role of DNAM-1 in the development of aGvHD in mice(18, 24). A study by Kanaya et al. (2008) showed that serum sDNAM-1 concentration prior to allogeneic hematopoietic stem cell transplantation was associated with the development of aGvHD, suggesting that sDNAM-1 is a 
unique biomarker for prediction of aGvHD. The study of 71 patients found that the incidence of GVHD in patients with high levels of soluble DNAM-1 at 7 days before transplantation was significantly higher than the patients with lower levels of DNAM-1. Their results showed that soluble DNAM-1 can be considered as a predictive marker of acute $\operatorname{GVHD}(38)$. In the present study, the criteria for selecting patients was having the DNAM-1 level more than $7 \mathrm{ng} / \mathrm{L}$. In this study, out of 10 enrolled patients, 5 patients faced aGvHD (3 patients in control group and 2 patients in MSCs recipient group). Given the limited number of samples in this study, it was not possible to measure the specificity and sensitivity of this marker to predict GvHD. In a study carried out by Kanaya et al. it was shown that DNAM-1 level pre transplant (-7_0 days) for sensivity of GvHD is $43 \%$ and for specificity is $82.6 \%$. In this study, $60 \%$ of control group and $40 \%$ of MSC recipient patients showed GvHD of the first 10 patients who initially had high level of DNAM-1. Given the role of MSCs in reducing GvHD occurrence, this marker is likely to be more sensitive in this study than the previous studies. However, only high DNAM-1 before allogeneic transplantation may not be sufficient to accurately predict aGvHD, and a combination of other predictive markers, coupled with high sDNAM-1 prior to allogeneic transplantation, will enable clinicians to Treatment of allo-HSCT patients with stronger preventive therapies for aGvHD. Although the results suggest that sDNAM-1 is produced by proteolytic degradation induced by MMP, the precise mechanism of sDNAM-1 production remains unclear. In addition, why healthy individuals show a wide range of serum sDNAM-1 levels and whether this range is due to the variability of MMP activity between healthy individuals is unclear. Past studies have shown that MMP activity is determinant in the development of aGvHD (14). For this reason, regarding the role of DNAM-1 in GvHD, it is hypothesized that patients with high MMP activity, which may have high serum levels of DNAM-1, have a high risk for aGvHD after allo-HSCT. DNAM-1 may also bind to CD155 on the surface of antigen-presenting cells or tissue of target organs. Since DNAM-1 has a ligand in common with TIGIT and CD96(68), this may interfere with the interaction of CD155 with TIGIT and CD96. Unlike DNAM-1, TIGIT and CD96 generate T cell inhibitory signals and suppress activation of effector T cells. Consequently, binding of DNAM-1 to CD155 suppresses the inhibitory signals generated by these two immunoreceptors in $\mathrm{T}$ cells, leading to increased $\mathrm{T}$ cell activity and worsened aGvHD. In fact, CD155 deficient mice receiving allogeneic hematopoietic grafts show increased risk of GvHD(69). Post-transplant DNAM-1 level did not differ significantly between the two groups on different days. However, a decrease in the level of DNAM-1 in a study by Nabekura in 2010 showed that DNAM-1 increases the proliferation of active alloreactive CD 8 $+\mathrm{T}$ cells and the production of IFN $\gamma$ by these cells(70). Past studies have also shown the important roles of this marker in modulating cellular immunity such as: 1) Increasing the cytotoxicity through cytotoxic T lymphocytes (CTLs) (including alloantigen-specific CTLs) and NK cells against target cells expressing CD155 and CD112 and increased secretion of cytokines such as IFN $\gamma, 2$ ) Proliferation and differentiation of CD4 + naive T cells to Th1 cells in corporation with LFA-1(71-74) . Given the suppressive role of MSCs, it can be implied that MSCs interfere with APCs and reduce antigen presentation to T cells, so it interfere the DNAM-1 stimulus function and consequently reduces the IFN $\alpha$ production by cells and decrease the inflammatory conditions. The level of TNFR1 at day 7 was higher in the GVHD group than in the nonGVHD group. In our study, the mean ST2 level was lower in MSC contained group, as it was decreased after +7 days. ST2 is a soluble receptor for interleukin-33 and is released from activated T cells during GVHD development and progression. In other words, elevated ST2 in the patient's blood indicates progression of GVHD. In a study by Matthew J. Hartwell and colleagues, an algorithm was designed based on biomarkers of patients 7 days after transplantation to identify the patients with high risk of GVHD and NRM (69). The decrease in ST2 levels from day +7 in patients treated with MSCs indicates the positive effect of these cells on immune suppression and decrease in the severity of GVHD in these patients. In another study by Mark T. Vander Lugt et al, ST2 was identified as the most significant marker for treatment-resistant GVHD and recurrent and death without recurrence. In this study, patients with high ST2 levels were 2.3 times more likely to develop refractory GVHD and relapse-free death compared with patients with low ST2 levels at baseline (75).

\section{Conclusion:}

According to this study, by considering the results of different factors such as ST2 and DNAM-1 and TNFR1, 
it was shown that the co-transplantation of HSCs and MSCs has no significant difference compared to the group received MSCs alone.

\section{Acknowledgment:}

This study has been supported by Taleghani Bone Marrow Transplantation ward, Tehran, Iran. The authors would like to thank the staffs and nursing team of Taleghani Bone Marrow Transplantation ward for their helping and appreciate Mr Arsalan Jalili for English language editing. The authors declare no conflict of interest in this study.

\section{Conflict Interest: None}

\section{Authors' Contributions :}

F.E; Sampling, performing tests, analyzing the data and writing the manuscript, Monitoring. S.K, M.S; Supporting In vitro tests, analyzing data and checking the results accuracy. A.H: Sampling, Injection, Monitoring. All authors read and approved the final manuscript.

\section{References:}

1. Negrin RS. Introduction to the review series on "Advances in hematopoietic cell transplantation". Am Soc Hematology; 2014.

2. Harris AC, Ferrara JL, Levine JE. Advances in predicting acute GVHD. British journal of haematology. 2013;160(3):288-302.

3. Qian L, Wu Z, Shen J. Advances in the treatment of acute graft-versus-host disease. Journal of cellular and molecular medicine. 2013;17(8):966-75.

4. Zhao K, Lou R, Huang F, Peng Y, Jiang Z, Huang K, et al. Immunomodulation effects of mesenchymal stromal cells on acute graft-versus-host disease after hematopoietic stem cell transplantation. Biology of Blood and Marrow Transplantation. 2015;21(1):97-104.

5. Wolf D, von Lilienfeld-Toal M, Wolf AM, Schleuning M, von Bergwelt-Baildon M, Held SA, et al. Novel treatment concepts for graft-versus-host disease. Blood, The Journal of the American Society of Hematology. 2012;119(1):16-25.

6. Lim J-Y, Park M-J, Im K-I, Kim N, Jeon E-J, Kim E-J, et al. Combination cell therapy using mesenchymal stem cells and regulatory T-cells provides a synergistic immunomodulatory effect associated with reciprocal regulation of $\mathrm{TH} 1 / \mathrm{TH} 2$ and th17/treg cells in a murine acute graft-versus-host disease model. Cell transplantation. 2014;23(6):703-14.

7. Bernardo M, Ball L, Cometa A, Roelofs H, Zecca M, Avanzini M, et al. Co-infusion of ex vivo-expanded, parental MSCs prevents life-threatening acute GVHD, but does not reduce the risk of graft failure in pediatric patients undergoing allogeneic umbilical cord blood transplantation. Bone marrow transplantation. $2011 ; 46(2): 200$.

8. Di Ianni M, Del Papa B, De Ioanni M, Moretti L, Bonifacio E, Cecchini D, et al. Mesenchymal cells recruit and regulate T regulatory cells. Experimental hematology. 2008;36(3):309-18.

9. Riley JL, June CH, Blazar BR. Human T regulatory cell therapy: take a billion or so and call me in the morning. Immunity. 2009;30(5):656-65.

10. Aggarwal S, Pittenger MF. Human mesenchymal stem cells modulate allogeneic immune cell responses. Blood. 2005;105(4):1815-22.

11. Ghannam S, Pène J, Moquet-Torcy G, Jorgensen C, Yssel H. Correction: mesenchymal stem cells inhibit human th17 cell differentiation and function and induce a $\mathrm{T}$ regulatory cell phenotype. The Journal of Immunology. 2013;191(11):5777-. 
12. Stenger EO, Krishnamurti L, Galipeau J. Mesenchymal stromal cells to modulate immune reconstitution early post-hematopoietic cell transplantation. BMC immunology. 2015;16(1):74.

13. Resnick IB, Barkats C, Shapira MY, Stepensky P, Bloom AI, Shimoni A, et al. Treatment of severe steroid resistant acute GVHD with mesenchymal stromal cells (MSC). American journal of blood research. $2013 ; 3(3): 225$.

14. Introna M, Lucchini G, Dander E, Galimberti S, Rovelli A, Balduzzi A, et al. Treatment of graft versus host disease with mesenchymal stromal cells: a phase I study on 40 adult and pediatric patients. Biology of blood and marrow transplantation. 2014;20(3):375-81.

15. Berger M, Signorino E, Muraro M, Quarello P, Biasin E, Nesi F, et al. Monitoring of TNFR1, IL-2R $\alpha$, HGF, CCL8, IL-8 and IL-12p70 following HSCT and their role as GVHD biomarkers in paediatric patients. Bone marrow transplantation. 2013;48(9):1230.

16. Perkins JD, Nelson DL, Rakela J, Grambsch PM, Krom R. Soluble interleukin-2 receptor level as an indicator of liver allograft rejection. Transplantation. 1989;47(1):77-81.

17. Ferrara JL, Harris AC, Greenson JK, Braun TM, Holler E, Teshima T, et al. Regenerating islet-derived 3-alpha is a biomarker of gastrointestinal graft-versus-host disease. Blood. 2011;118(25):6702-8.

18. Lee SH, Lee M, Yoo K, Kim D, Son M, Sung K, et al. Co-transplantation of third-party umbilical cord blood-derived MSCs promotes engraftment in children undergoing unrelated umbilical cord blood transplantation. Bone marrow transplantation. 2013;48(8):1040-5.

19. Choi SW, Kitko CL, Braun T, Paczesny S, Yanik G, Mineishi S, et al. Change in plasma tumor necrosis factor receptor 1 levels in the first week after myeloablative allogeneic transplantation correlates with severity and incidence of GVHD and survival. Blood. 2008;112(4):1539-42.

20. August K, Chiang K, Bostick R, Flanders W, Waller E, Langston A, et al. Biomarkers of immune activation to screen for severe, acute GVHD. Bone marrow transplantation. 2011;46(4):601.

21. Marafini I, Di Sabatino A, Zorzi F, Monteleone I, Sedda S, Cupi M, et al. Serum regenerating islet-derived 3 -alpha is a biomarker of mucosal enteropathies. Alimentary pharmacology \& therapeutics. 2014;40(8):97481.

22. Ito S, Barrett AJ. ST2: the biomarker at the heart of GVHD severity. Blood. 2015;125(1):10-1.

23. Kanaya M, Shibuya K, Hirochika R, Kanemoto M, Ohashi K, Okada M, et al. Soluble DNAM-1, as a predictive biomarker for acute graft-versus-host disease. PloS one. 2016;11(6):e0154173.

24. Baron F, Lechanteur C, Willems E, Bruck F, Baudoux E, Seidel L, et al. Cotransplantation of mesenchymal stem cells might prevent death from graft-versus-host disease (GVHD) without abrogating graft-versustumor effects after HLA-mismatched allogeneic transplantation following nonmyeloablative conditioning. Biology of blood and marrow transplantation. 2010;16(6):838-47.

25. Kallekleiv M, Larun L, Bruserud Ø, Hatfield KJ. Co-transplantation of multipotent mesenchymal stromal cells in allogeneic hematopoietic stem cell transplantation: a systematic review and meta-analysis. Cytotherapy. $2016 ; 18(2): 172-85$.

26. Bacigalupo A. Mesenchymal stem cells and haematopoietic stem cell transplantation. Best Practice \& Research Clinical Haematology. 2004;17(3):387-99.

27. Tian Y, Deng Y, Huang Y, Wang Y. Bone marrow-derived mesenchymal stem cells decrease acute graftversus-host disease after allogeneic hematopoietic stem cells transplantation. Immunological investigations. 2008;37(1):29-42.

28. Liu K, Chen Y, Zeng Y, Xu L, Liu D, Chen H, et al. Coinfusion of mesenchymal stromal cells facilitates platelet recovery without increasing leukemia recurrence in haploidentical hematopoietic stem cell 
transplantation: a randomized, controlled clinical study. Stem cells and development. 2011;20(10):1679-85.

29. Koç ON, Gerson SL, Cooper BW, Dyhouse SM, Haynesworth SE, Caplan AI, et al. Rapid hematopoietic recovery after coinfusion of autologous-blood stem cells and culture-expanded marrow mesenchymal stem cells in advanced breast cancer patients receiving high-dose chemotherapy. Journal of Clinical Oncology. 2000;18(2):307-.

30. Angelopoulou M, Novelli E, Grove JE, Rinder HM, Civin C, Cheng L, et al. Cotransplantation of human mesenchymal stem cells enhances human myelopoiesis and megakaryocytopoiesis in NOD/SCID mice. Experimental hematology. 2003;31(5):413-20.

31. Bartholomew A, Sturgeon C, Siatskas M, Ferrer K, McIntosh K, Patil S, et al. Mesenchymal stem cells suppress lymphocyte proliferation in vitro and prolong skin graft survival in vivo. Experimental hematology. $2002 ; 30(1): 42-8$.

32. Krampera M, Glennie S, Dyson J, Scott D, Laylor R, Simpson E, et al. Bone marrow mesenchymal stem cells inhibit the response of naive and memory antigen-specific T cells to their cognate peptide. Blood. 2003;101(9):3722-9.

33. William TT, Pendleton JD, Beyer WM, Egalka MC, Guinan EC. Suppression of allogeneic T-cell proliferation by human marrow stromal cells: implications in transplantation. Transplantation. 2003;75(3):389-97.

34. Frassoni F. Expanded mesenchymal stem cells (MSC), co-infused with HLA identical hemopoietic stem cell transplants, reduce acute and chronic graft-versus-host disease: a matched pair analysis. Bone Marrow Transplant. 2002;29:S2.

35. Le Blanc K, Rasmusson I, Sundberg B, Götherström C, Hassan M, Uzunel M, et al. Treatment of severe acute graft-versus-host disease with third party haploidentical mesenchymal stem cells. The Lancet. 2004;363(9419):1439-41.

36. Zhao K, Liu Q. The clinical application of mesenchymal stromal cells in hematopoietic stem cell transplantation. Journal of hematology \& oncology. 2016;9(1):46.

37. Nasef A. Role of Bone Marrow Derived Mesenchymal Stem Cells in Management of Graft Versus Host Disease. Stem Cell Biology in Normal Life and Diseases: IntechOpen; 2013.

38. Lazarus HM, Koc ON, Devine SM, Curtin P, Maziarz RT, Holland HK, et al. Cotransplantation of HLA-identical sibling culture-expanded mesenchymal stem cells and hematopoietic stem cells in hematologic malignancy patients. Biology of blood and marrow transplantation. 2005;11(5):389-98.

39. Ringdén O, Labopin M, Gorin N-C, Le Blanc K, Rocha V, Gluckman E, et al. Treatment with granulocyte colony-stimulating factor after allogeneic bone marrow transplantation for acute leukemia increases the risk of graft-versus-host disease and death: a study from the Acute Leukemia Working Party of the European Group for Blood and Marrow Transplantation. Journal of clinical oncology. 2004;22(3):416-23.

40. Wu K-H, Tsai C, Wu H-P, Sieber M, Peng C-T, Chao Y-H. Human application of ex vivo expanded umbilical cord-derived mesenchymal stem cells: enhance hematopoiesis after cord blood transplantation. Cell transplantation. 2013;22(11):2041-51.

41. Chao Y, Tsai C, Peng C, Wu H, Chan C, Weng T, et al. Cotransplantation of umbilical cord MSCs to enhance engraftment of hematopoietic stem cells in patients with severe aplastic anemia. Bone marrow transplantation. 2011;46(10):1391-2.

42. Macmillan M, Blazar B, DeFor T, Wagner J. Transplantation of ex-vivo culture-expanded parental haploidentical mesenchymal stem cells to promote engraftment in pediatric recipients of unrelated donor umbilical cord blood: results of a phase I-II clinical trial. Bone marrow transplantation. 2009;43(6):447.

43. Kimura T, Asada R, Wang J, Kimura T, Morioka M, Matsui K, et al. Identification of Long-Term 
Repopulating Potential of Human Cord Blood-Derived CD34- flt3- Severe Combined ImmunodeficiencyRepopulating Cells by Intra-Bone Marrow Injection. Stem Cells. 2007;25(6):1348-55.

44. Pereira R, Halford K, O'hara M, Leeper D, Sokolov B, Pollard M, et al. Cultured adherent cells from marrow can serve as long-lasting precursor cells for bone, cartilage, and lung in irradiated mice. Proceedings of the national academy of sciences. 1995;92(11):4857-61.

45. Bensidhoum M, Chapel A, Francois S, Demarquay C, Mazurier C, Fouillard L, et al. Homing of in vitro expanded Stro-1-or Stro-1+ human mesenchymal stem cells into the NOD/SCID mouse and their role in supporting human CD34 cell engraftment. Blood. 2004;103(9):3313-9.

46. Devine SM, Bartholomew AM, Mahmud N, Nelson M, Patil S, Hardy W, et al. Mesenchymal stem cells are capable of homing to the bone marrow of non-human primates following systemic infusion. Experimental hematology. 2001;29(2):244-55.

47. Horwitz E, Dominici M. How do mesenchymal stromal cells exert their therapeutic benefit? Cytotherapy. 2008;10(8):771-4.

48. Honczarenko M, Le Y, Swierkowski M, Ghiran I, Glodek AM, Silberstein LE. Human bone marrow stromal cells express a distinct set of biologically functional chemokine receptors. Stem cells. 2006;24(4):103041.

49. Majumdar MK, Thiede MA, Mosca JD, Moorman M, Gerson SL. Phenotypic and functional comparison of cultures of marrow-derived mesenchymal stem cells (MSCs) and stromal cells. Journal of cellular physiology. 1998;176(1):57-66.

50. Ponomaryov T, Peled A, Petit I, Taichman RS, Habler L, Sandbank J, et al. Induction of the chemokine stromal-derived factor-1 following DNA damage improves human stem cell function. The Journal of clinical investigation. 2000;106(11):1331-9.

51. Le Blanc K, Samuelsson H, Gustafsson B, Remberger M, Sundberg B, Arvidson J, et al. Transplantation of mesenchymal stem cells to enhance engraftment of hematopoietic stem cells. Leukemia. 2007;21(8):1733.

52. Wang L, Zhang H, Guan L, Zhao S, Gu Z, Wei H, et al. Mesenchymal stem cells provide prophylaxis against acute graft-versus-host disease following allogeneic hematopoietic stem cell transplantation: A metaanalysis of animal models. Oncotarget. 2016;7(38):61764.

53. Djouad F, Plence P, Bony C, Tropel P, Apparailly F, Sany J, et al. Immunosuppressive effect of mesenchymal stem cells favors tumor growth in allogeneic animals. Blood. 2003;102(10):3837-44.

54. Ball LM, Bernardo ME, Roelofs H, Lankester A, Cometa A, Egeler RM, et al. Cotransplantation of ex vivo-expanded mesenchymal stem cells accelerates lymphocyte recovery and may reduce the risk of graft failure in haploidentical hematopoietic stem-cell transplantation. Blood. 2007;110(7):2764-7.

55. Majumdar MK, Thiede MA, Haynesworth SE, Bruder SP, Gerson SL. Human marrow-derived mesenchymal stem cells (MSCs) express hematopoietic cytokines and support long-term hematopoiesis when differentiated toward stromal and osteogenic lineages. Journal of hematotherapy \& stem cell research. $2000 ; 9(6): 841-8$.

56. Uyttenhove C, Pilotte L, Theate I, Stroobant V, Colau D, Parmentier N, et al. Evidence for a tumoral immune resistance mechanism based on tryptophan degradation by indoleamine 2, 3-dioxygenase. Nature medicine. 2003;9(10):1269.

57. Olerup O, Zetterquist H. HLA-DR typing by PCR amplification with sequence-specific primers (PCRSSP) in 2 hours: an alternative to serological DR typing in clinical practice including donor-recipient matching in cadaveric transplantation. Tissue antigens. 1992;39(5):225-35.

58. Copelan E, Biggs J, Szer J, Thompson J, Crilley P, Brodsky I, et al., editors. Allogeneic bone marrow transplantation for acute myelogenous leukemia, acute lymphocytic leukemia, and multiple myeloma 
following preparation with busulfan and cyclophosphamide (BuCy2). Seminars in oncology; 1993.

59. Socie G, Clift RA, Blaise D, Devergie A, Ringden O, Martin PJ, et al. Busulfan plus cyclophosphamide compared with total-body irradiation plus cyclophosphamide before marrow transplantation for myeloid leukemia: long-term follow-up of 4 randomized studies. Blood. 2001;98(13):3569-74.

60. Clift R, Buckner C, Thomas E, Bensinger W, Bowden R, Bryant E, et al. Marrow transplantation for chronic myeloid leukemia: a randomized study comparing cyclophosphamide and total body irradiation with busulfan and cyclophosphamide. Blood. 1994;84(6):2036-43.

61. Storb R, Deeg HJ, Fisher L, Appelbaum F, Buckner CD, Bensinger W, et al. Cyclosporine v methotrexate for graft-v-host disease prevention in patients given marrow grafts for leukemia: long-term follow-up of three controlled trials. Blood. 1988;71(2):293-8.

62. Przepiorka D, Weisdorf D, Martin P, Klingemann H, Beatty P, Hows J, et al. 1994 Consensus conference on acute GVHD grading. Bone marrow transplantation. 1995;15(6):825-8.

63. Atkinson K, Horowitz M, Gale R, Lee M, Rimm A, Bortin M. Consensus among bone marrow transplanters for diagnosis, grading and treatment of chronic graft-versus-host disease. Committee of the International Bone Marrow Transplant Registry. Bone marrow transplantation. 1989;4(3):247-54.

64. Di Nicola M, Carlo-Stella C, Magni M, Milanesi M, Longoni PD, Matteucci P, et al. Human bone marrow stromal cells suppress T-lymphocyte proliferation induced by cellular or nonspecific mitogenic stimuli. Blood. 2002;99(10):3838-43.

65. Troeger A, Meisel R, Moritz T, Dilloo D. Immunotherapy in allogeneic hematopoietic stem cell transplantationnot just a case for effector cells. Bone marrow transplantation. 2005;35(S1):S59.

66. Ramasamy R, Lam EW, Soeiro I, Tisato V, Bonnet D, Dazzi F. Mesenchymal stem cells inhibit proliferation and apoptosis of tumor cells: impact on in vivo tumor growth. Leukemia. 2007;21(2):304-10.

67. Ning H, Yang F, Jiang M, Hu L, Feng K, Zhang J, et al. The correlation between cotransplantation of mesenchymal stem cells and higher recurrence rate in hematologic malignancy patients: outcome of a pilot clinical study. Leukemia. 2008;22(3):593.

68. Levine JE, Logan BR, Wu J, Alousi AM, Bolanos-Meade J, Ferrara JL, et al. Acute graft-versushost disease biomarkers measured during therapy can predict treatment outcomes: a Blood and Marrow Transplant Clinical Trials Network study. Blood. 2012;119(16):3854-60.

69. Vander Lugt MT, Braun TM, Hanash S, Ritz J, Ho VT, Antin JH, et al. ST2 as a marker for risk of therapy-resistant graft-versus-host disease and death. New England Journal of Medicine. 2013;369(6):529-39.

70. Shibuya A, Campbell D, Hannum C, Yssel H, Franz-Bacon K, McClanahan T, et al. DNAM-1, a novel adhesion molecule involved in the cytolytic function of T lymphocytes. Immunity. 1996;4(6):573-81.

71. Nabekura T, Kanaya M, Shibuya A, Fu G, Gascoigne NR, Lanier LL. Costimulatory molecule DNAM-1 is essential for optimal differentiation of memory natural killer cells during mouse cytomegalovirus infection. Immunity. 2014;40(2):225-34.

72. Bottino C, Castriconi R, Pende D, Rivera P, Nanni M, Carnemolla B, et al. Identification of PVR (CD155) and Nectin-2 (CD112) as cell surface ligands for the human DNAM-1 (CD226) activating molecule. Journal of Experimental Medicine. 2003;198(4):557-67.

73. Tahara-Hanaoka S, Shibuya K, Kai H, Miyamoto A, Morikawa Y, Ohkochi N, et al. Tumor rejection by the poliovirus receptor family ligands of the DNAM-1 (CD226) receptor. Blood. 2006;107(4):1491-6.

74. Hartwell MJ, Ozbek U, Holler E, Renteria AS, Major-Monfried H, Reddy P, et al. An early-biomarker algorithm predicts lethal graft-versus-host disease and survival. JCI insight. 2017;2(3). 
75. Huang X, Liu D, Liu K, Xu L, Chen H, Han W, et al. Haploidentical hematopoietic stem cell transplantation without in vitro T-cell depletion for the treatment of hematological malignancies. Bone marrow transplantation. 2006;38(4):291.

\section{Figure legend:}

Figure1: Karyotyping of bone marrow MSCs. Figure 1a shows the chromosomal pattern of the first donor and $1 \mathrm{~b}$ is for the second donor.

Figure 2: diagram showing the trens of DNAM in MSC recipient group

Figure 3: diagram showing the trends of TNFR in MSC recipient group

Figure 4: diagram showing the trends of ST2 in MSC recipient group

Figure 5: DNAM-1 ratio on different days after transplantation in two groups

Figure 6: ST2 ratio on different days after transplantation in two groups

Figure 7: TNFR ratio on different days after transplantation in two groups

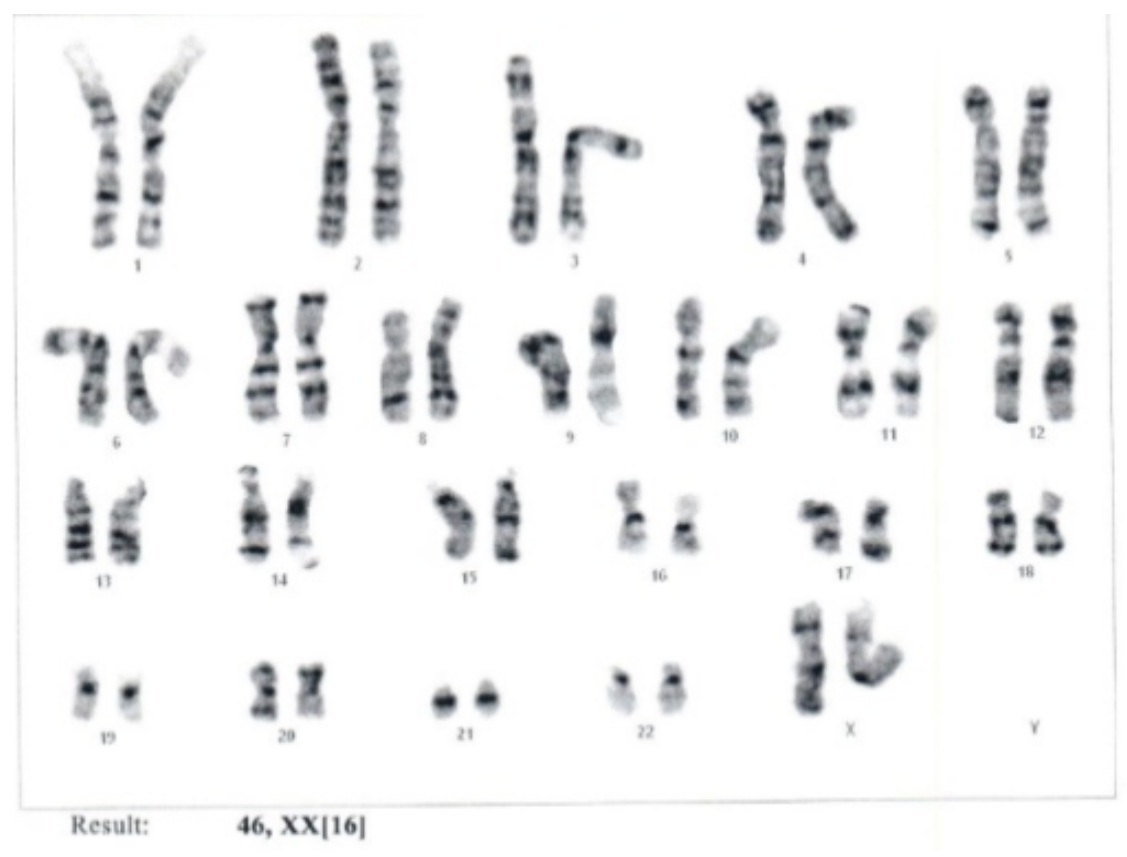



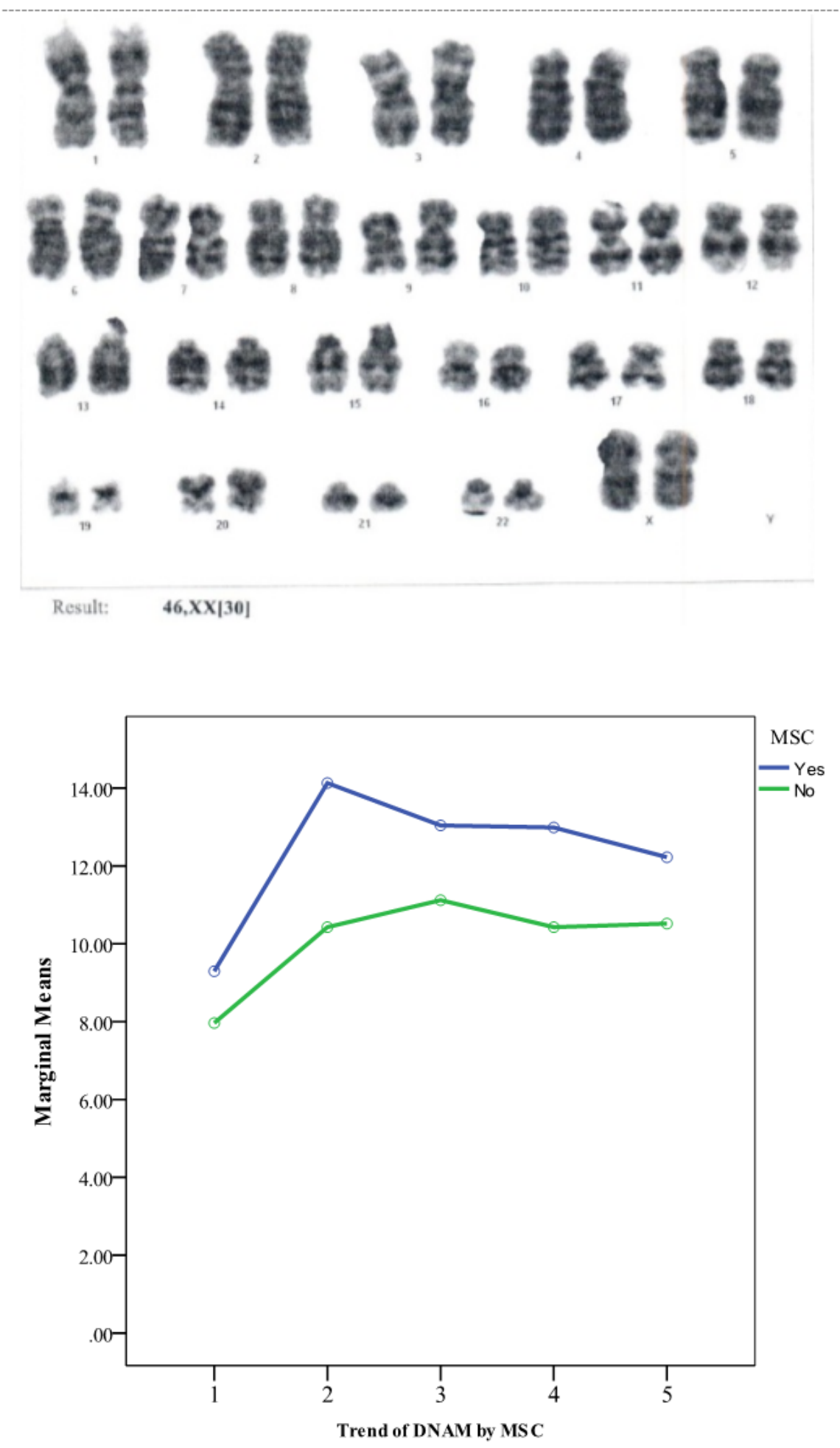

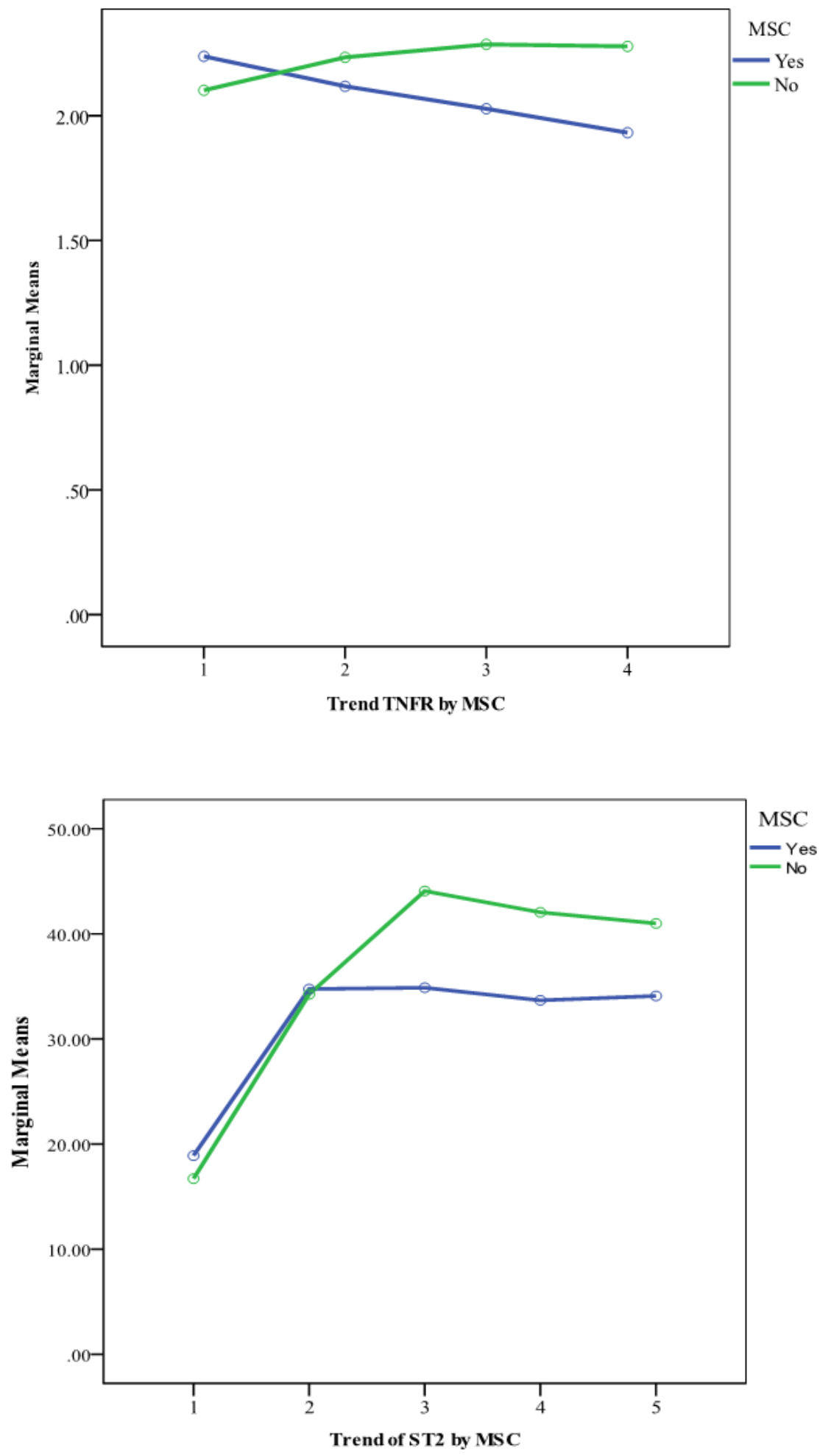

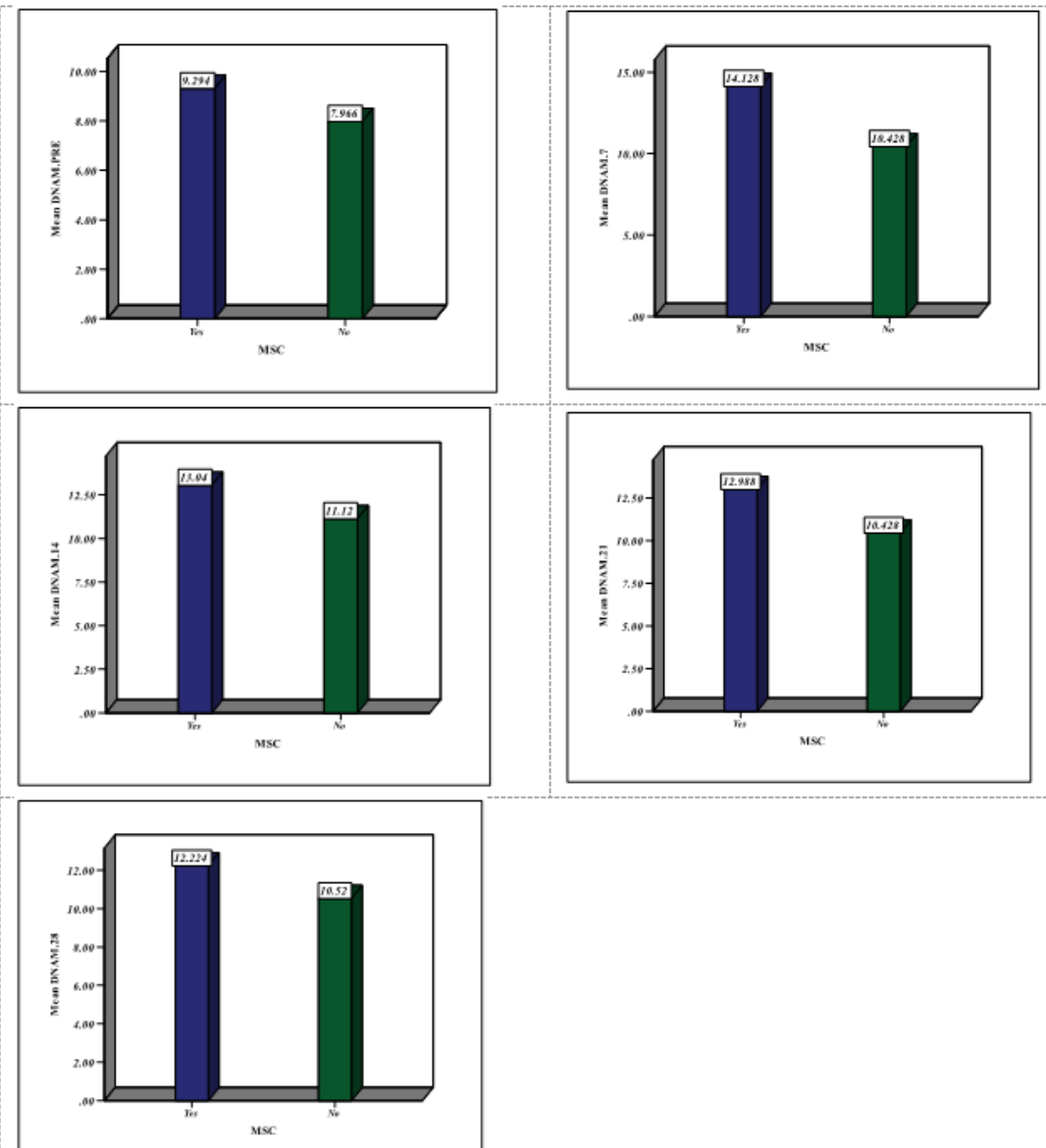

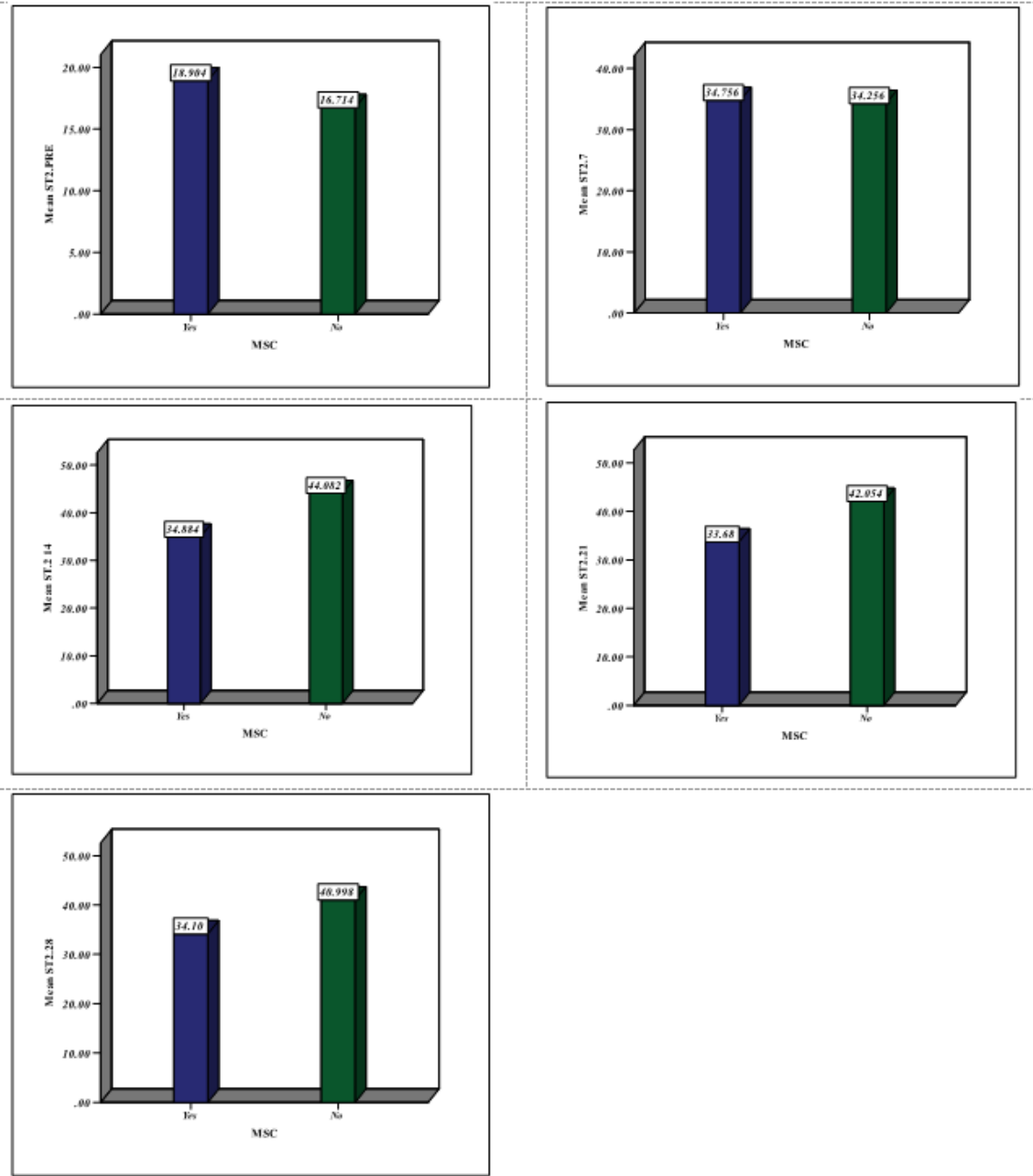

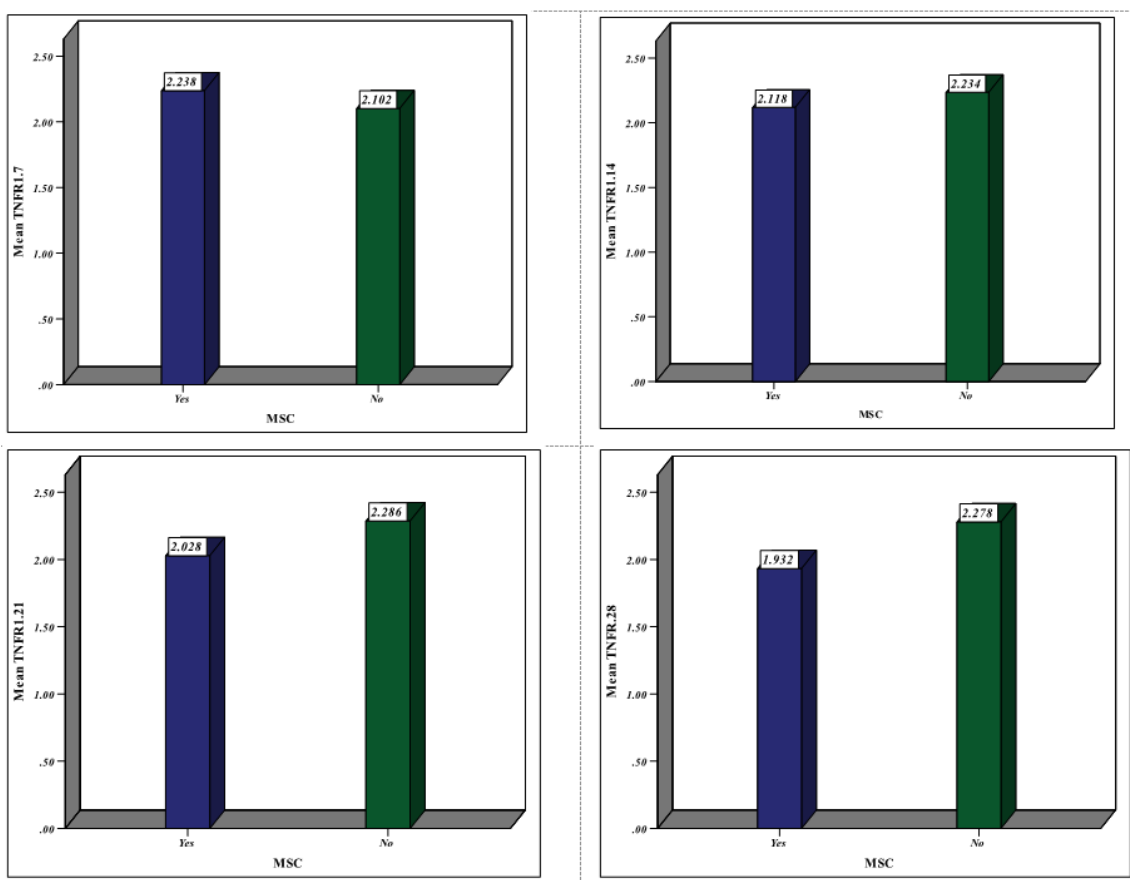